\title{
Estudo Molecular de Vibrio cholerae não-01 isolado de zooplâncton da Baía de São Marcos/São Luis - MA, Brasil
}

\author{
Molecular study of Vibrio cholerae non-01 isolated from zooplankton \\ of São Marcos Bay/São Luis - MA, Brasil
}

\author{
Eloisa da Graça do Rosario Gonçalves ${ }^{1}$, Nilma Cintra Leal ${ }^{2}$ e Ernesto Hofer ${ }^{3}$
}

\begin{abstract}
RESUM0
O estudo foi desenvolvido com o objetivo de analisar o perfil plasmidial, pesquisar genes de virulência e identificar os perfis genéticos de 31 cepas de Vibrio cholerae não 01 isoladas de zooplâncton dos estuários dos rios Anil e Bacanga em São Luis MA. 0 estudo do DNA plasmidial revelou a presença de 2 a 3 plasmídeos em 10 cepas, com pesos moleculares variando de 5,5 a 40 kilobases. A ribotipagem revelou um perfil comum a todas as cepas. A amplificação do DNA genômico por PCR não revelou os genes ctxA, ace e zot, mostrando tratar-se de cepas não patogênicas, enquanto a RAPD-PCR identificou múltiplos perfis genéticos, achado compatível com o grande potencial de variabilidade desta espécie.
\end{abstract}

Palavras-chaves: Vibrio cholerae não 01. Baía de São Marcos. Ecologia. Estudo molecular.

\begin{abstract}
The study was developed to analyze the plasmidial DNA, research virulence genes and identify genetic diversity of 31 strains of Vibrio cholerae non-01 isolated from zooplankton of the Bacanga and Anil rivers in São Luis-MA. The study of plasmidial DNA showed 2 or 3 plasmids from 10 strains between 5.5 and 40 kilobasis. There was only single ribotype pattern. PCR methods did not show the genes ctxA, ace and zot, while RADP-PCR identified genetic diversity in the strains, showing the potential for variability in this species.
\end{abstract}

Key-words: Vibrio cholerae non-01. São Marcos bay. Ecology. Molecular study.

A espécie Vibrio cholerae, integrante natural da flora bacteriana de ambientes aquáticos ${ }^{9}$ está classificada em 140 sorogrupos, com base nas características do antígeno somático " 0 "23. Conversões sorológicas foram demonstradas entre os sorogrupos em condições controladas no laboratório, com perda da aglutinabilidade de $\mathrm{V}$. cholerae 01 e aquisição dessa característica por vibrios não- $01^{3620}$.

Poucos estudos sobre a ecologia desta bactéria foram desenvolvidos em condições naturais. Inicialmente, a demonstração dos sorogrupos não-01 no meio ambiente não costumava despertar a atenção como um potencial problema de saúde pública com a identificação do sorogrupo 0139 na etiologia de doença diarréica idêntica à cólera clássica, em 1992, nos países banhados pela Baía de Bengala, desfez-se a convicção de que só o sorogrupo 01 seria capaz de produzir cólera epidêmica ${ }^{1}$. Estudos moleculares recentes têm demonstrado 0 grande potencial de variabilidade genética e a dinâmica de transferência horizontal de genes de virulência entre os diferentes sorogrupos, reforçando o potencial de patogenicidade desta espécie $^{712}$.

0 município de São Luis está situado às margens da Baía de São Marcos, onde deságuam os rios Anil e Bacanga, cujas nascentes encontram-se no interior da Ilha de São Luis. As populações ribeirinhas dos dois estuários mantêm-se em estreito contacto com 0 ambiente aquático em atividades de pesca e de lazer, expostas ao risco de infecção. 0 presente estudo foi

1. Departamento de Patologia da Universidade Federal do Maranhão, São Luis, MA. 2. Centro de Pesquisa Ageu Magalhães da Fundação Instituto Oswaldo Cruz, Recife, PE. 3. Laboratório de Zoonoses Bacterianas da Fundação Instituto Oswaldo Cruz, Rio de Janeiro, RJ.

Apoio finaceiro: CAPES

Endereço para correspondência: Dra. Eloisa da Graça do Rosario Gonçalves. Depto de Patologia/UFMA. Praça Madre Deus 2, Térreo, Bairro Madre Deus, 65025-560 São Luis, MA

Telefone: 5598 221-0270

e-mail: regionalsbmt@elo.com.br

Recebido para publicação em 16/10/2003

Aceito em 19/05/2004 
desenvolvido com o objetivo de analisar o perfil genético, assim como pesquisar a existência de genes de virulência em cepas de Vibrio cholerae isoladas em amostras de zooplâncton coletadas no referido ambiente.

\section{MATERIAL E MÉTODOS}

Amostras de zooplancton foram coletadas de Outubro de 1997 a Outubro de 1998, em intervalos mensais, elegendo-se duas estações fixas de amostragem (1 e 2), nos estuários dos rios Anil e Bacanga, os quais deságuam na Baía de São Marcos, São Luis - MA. Foi empregada no processo, rede de plâncton, confeccionada em malha de $65 \mathrm{~mm}$ de abertura, em arrastos horizontais, subsuperficiais, por 5 minutos, cobrindo raio de cinco metros. Amostras de $400 \mathrm{ml}$ de água, contendo zooplâncton, foram mantidas em frasco estéril e à temperatura ambiente, sendo submetidas em, no máximo duas horas, ao processo clássico de isolamento bacterian $0^{8}$.

Para 0 estudo do DNA plasmidial das cepas isoladas foi empregada a técnica de extração do DNA por lise alcalina, sem adição de lisozima ${ }^{4}$. 0 material obtido foi submetido à eletroforese em Gel de Agarose 0,6\% em tampão TBE (Trisborato 0,089M; ácido bórico 0,098M; EDTA 0,002M). A migração deu-se em temperatura ambiente, empregando-se corrente constante de $20 \mathrm{~mA}$ e $100 \mathrm{~V}$, por duas horas. 0 DNA foi corado com brometo de etídio ( $15 \mathrm{mg} / \mathrm{ml}$ ) e observado em transiluminador de luz ultravioleta (UV). 0 peso molecular dos plasmídeos foi estimado pela comparação com plasmídeos previamente conhecidos, presentes na cepa controle, Escherichia coli 39R861.

Para a detecção dos genes de virulência - ctxA( enterotoxina da cólera) , ace ( enterotoxina acessória da cólera) e zot ( toxina da zona ocludens) - 0 DNA total foi extraído pela técnica descrita por Maniatis e $\mathrm{col}^{15}$, sendo empregada PCR em sua amplificação, com os seguintes iniciadores:

Para o gene ctxA: 5' CTC AGA CGG GAT TTG TTA GGC ACG 3' e 5' TCT ATCTCT GTA GCCCCT ATT ACG 3', descritos por Keasler e Hall ${ }^{13}$.

Para 0 gene ace : 5' AGA GCG CTG CAT TTA TCC TTA TTG 3' e 5' AAC TCG GTC TCG GCC TCT CGT ATC 3'.

Para 0 gene zot: 5' GCT ATC GAT ATG CTG TCT CCT CAA 3' e 5' AAA GCC GAC CAA TAC AAA AAC CAA 3'.

Os dois últimos pares de iniciadores foram construídos a partir de seqüências disponíveis no GenBank, cuja senha de acesso é AF 175708, utilizando-se 0 programa DNAstar. As reações foram preparadas em volume final de $25 \mathrm{ml}$ por tubo, contendo 20ng de DNAmolde; Tris-HCL10mM; KCL50mM; $\mathrm{MgCl}_{2}$ 1,5 mM; 2 ml de dNTP 200mM de cada nucleotídeo (Pharmacia); 20pmol de cada "primer" e 1 U de Taq DNA polimerase (Pharmacia). Em cada partida de amplificação foi incluído um controle positivo (DNA da cepa de referência V. cholerae 01 569B, Clássico/Inaba) e um controle negativo (todos os componentes da mistura de reação, exceto o DNA). As amplificações foram feitas em termociclador Perkin Elmer, programado para 30 ciclos de 1 minuto a $92^{\circ} \mathrm{C}$ para a desnaturação do DNA, 1 minuto a $55^{\circ} \mathrm{C}$ para anelamento dos iniciadores e 2 minutos a $72^{\circ} \mathrm{C}$, para 0 alongamento ou síntese de DNA, terminando por uma etapa de 7 minutosa $72^{\circ} \mathrm{C}$ para alongamento final das fitas.

Dez microlitros dos produtos das amplificações foram submetidos à eletroforese em gel de agarose 1\%, no tampão TBE, a 100V e 200mA. 0 gel foi corado com Brometo de etídio, sendo o DNA visualizado em transiluminador de luz ultravioleta (UV) e fotografado em Polaroide.

0 perfil genético das cepas foi estudado através de RAPDPCR, empregando-se os iniciadores 784 (5'GCG GAA ATA G3') e 791 (5' GAG GAC AAA G 3'). As reações foram desenvolvidas em volume final de $25 \mathrm{ml}$ por tubo, contendo 20ng de DNA molde; 2,5ml do tampão de raeção $10 \mathrm{x}$ concentrado ( tris- $\mathrm{HCl} 100 \mathrm{mM}$; $\mathrm{KCl} 500 \mathrm{mM} ; \mathrm{MgCl}_{2} 3,0 \mathrm{mM} ; 2,5 \mathrm{ml}$ de dNTP 200mM ( Pharmacia) . Foi utilizado termociclador (Perkin Elmer) programado para 30 ciclos de 1 minuto a $94^{\circ} \mathrm{C}, 1$ minuto a $36^{\circ} \mathrm{C}$ e 2 minutos a $72^{\circ} \mathrm{C}$. Finalmente, 10 microlitros dos produtos das amplificações foram submetidos à eletroforese em gel de agarose 1\%, nas condições anteriormente descritas.

A técnica de ribotipagem por PCR, descrita por Kostman e cols ${ }^{14}$, foi empregada, utilizando-se os iniciadores 1 (5’TTT CTG CAG YGG NTG GAT CAC CTC CTT 3') e 2 ( 5' ACG AAT TCT GAC TGC CMR GGC ATC CA 3'), desenhados por Chun e $\mathrm{col}^{5}$.

\section{RESULTAD0S}

Foram obtidos 55 isolados de $\mathrm{V}$. cholerae não 01,48 (87,3\%) provenientes do Rio Bacanga e 7 ( 12,7\%), do Rio Anil, dos quais 31 foram submetidos ao estudo molecular. Estes isolados são provenientes das amostras coletadas entre os meses de dezembro de 1997 e abril de 1998, estando a distribuição temporal e espacial representada na Tabela 1. Um isolado de V. alginolyticus, três de V. parahaemolyticus e 1 de Vibrio sp foram incluídos no estudo a título experimental e para confronto com 0 perfil de $\mathrm{V}$. cholerae.

Dos 31 isolados, 10 (32,2\%) exibiram de 2 a 3 plasmídeos, com pesos moleculares variando entre 5,5 e 40 kilobases (Figura 1).

Tabela 1 - Distribuição têmporo-espacial de 31 isolados de Vibrio cholerae não 01, não O139 submetidos a estudo molecular - São Luis/MA( outubro de 1997 a outubro de 1998).

\begin{tabular}{|c|c|c|c|c|}
\hline \multirow[b]{3}{*}{ Ano/mês } & \multicolumn{4}{|c|}{ Isolados bacterianos } \\
\hline & \multicolumn{2}{|c|}{ Rio Bacanga } & \multicolumn{2}{|c|}{ Rio Anil } \\
\hline & Estação 1 & Estação 2 & Estação 1 & Estação 2 \\
\hline \multicolumn{5}{|l|}{1997} \\
\hline dez & - & - & - & $1 ; 2 \mathrm{a} ; 2 \mathrm{~b} * 3 ; 4^{* *}$ \\
\hline \multicolumn{5}{|l|}{1998} \\
\hline jan & $5 ; 6 ; 7 ; 8 ; 9$ & - & - & - \\
\hline fev & $10 ; 13 ; 14$ & $11 ; 12$ & - & - \\
\hline $\operatorname{mar}$ & 17 & $15 ; 16$ & $21^{* *}$ & $18 ; 19 ; 20 * * ; 22$ \\
\hline$a b r$ & $\begin{array}{c}23 ; 24 ; 29 ; \\
30 ; 31 * * * ; 32\end{array}$ & $\begin{array}{c}25 ; 26 ; 27 ; 28 ; \\
33 ; 34 ; 35\end{array}$ & - & - \\
\hline
\end{tabular}


Não foram detectados os genes de toxigenicidade ctxA, zot ou ace em nenhum dos 31 isolados, pela técnica de PCR.

Nas Figuras 2 e 3 estão representados os produtos da RAPDPCR. Com o emprego do iniciador 791 foram identificados 13 perfis genéticos diferentes, com amplificação de 2 a 9 bandas entre 600 e 2000 pares de bases, enquanto 7 grupos genotípicos

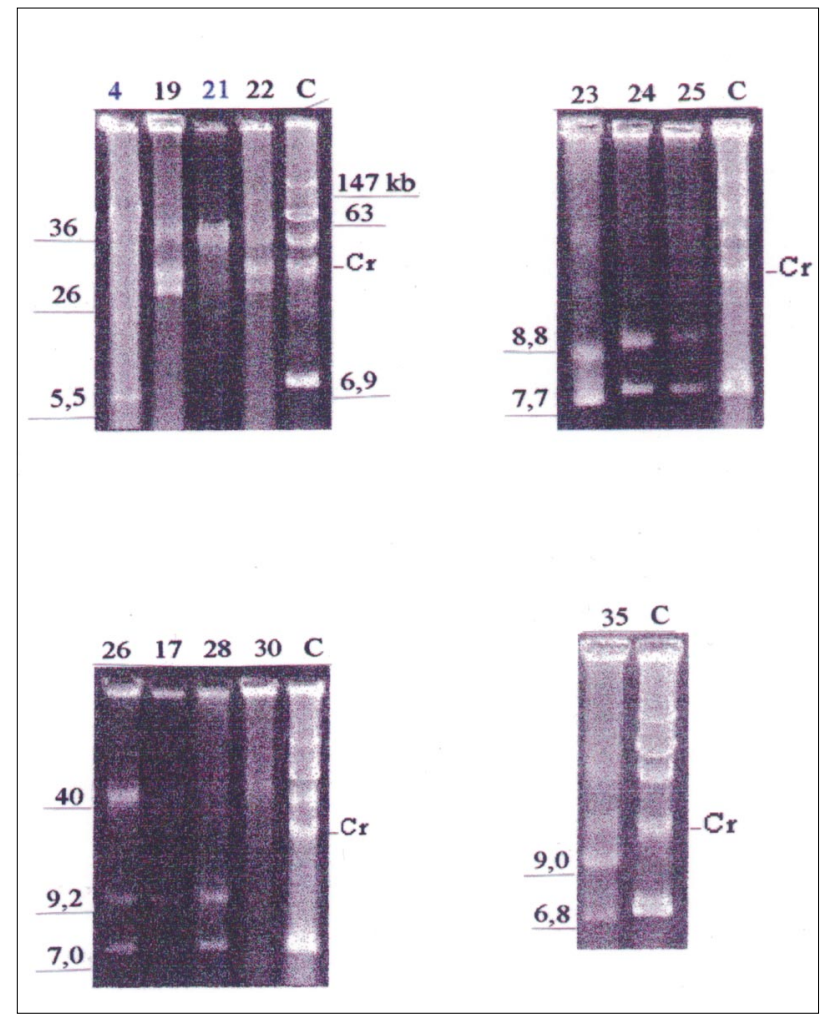

Figura 1 - Produtos de extração do DNA plasmidial de cepas de Vibrio cholerae não 01. $\mathrm{Cr}=\mathrm{DNA}$ cromossômico. Linhas $\mathrm{C}=$ controle $(\mathrm{E}$. coli 39R861). Linhas 4 e 21+V. parahaemolyticus. Linhas 19, 22-28, 30, 35+ Vibrio cholerae não 01.

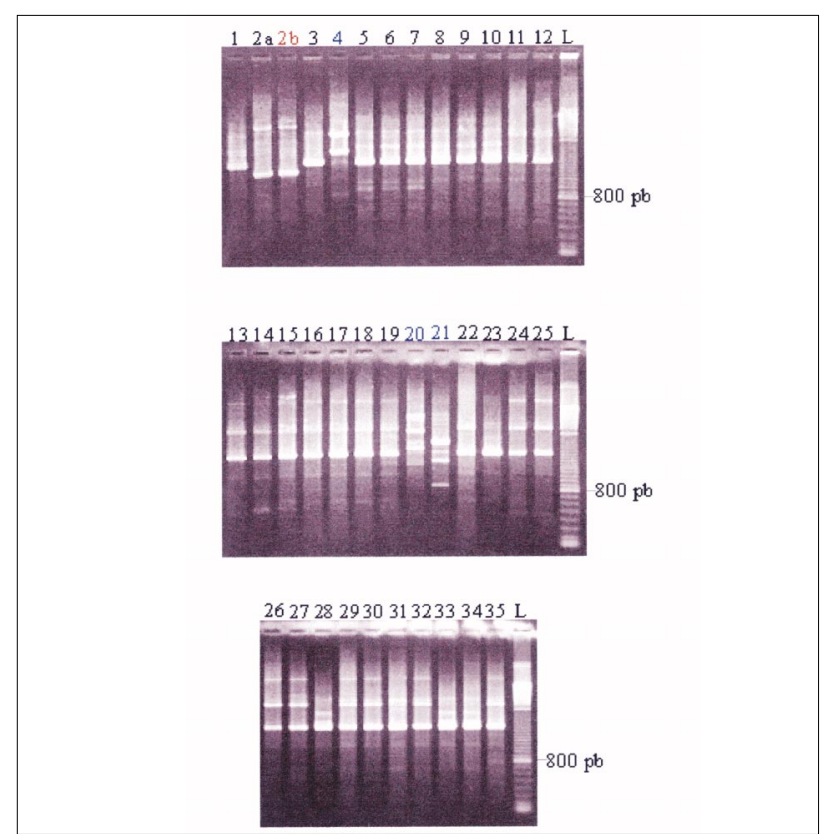

Figura 2 - RAPD-PCR: Produtos de amplificação do DNA de cepas de Vibrio cholerae não 01 com primer 784 - São Luís/MA (1997-1998). L= ladder, pb= parde bases. Linhas 1, 2a, 3,5-19, 22-30, 32-35=V. cholerae não 01. Linha 2b= V. alginolyticus; Linha 31= Vibrio sp, linhas 4,20,21= V. parahaemolyticus . foram demonstrados com 0 iniciador 784, havendo amplificação de 2 a 4 bandas, variando entre 150 a mais de 2000 pares de bases.

A ribotipagem por PCR mostrou padrão de amplificação idêntico nos 31 isolados não 01, conforme gel representativo mostrado na Figura 4.

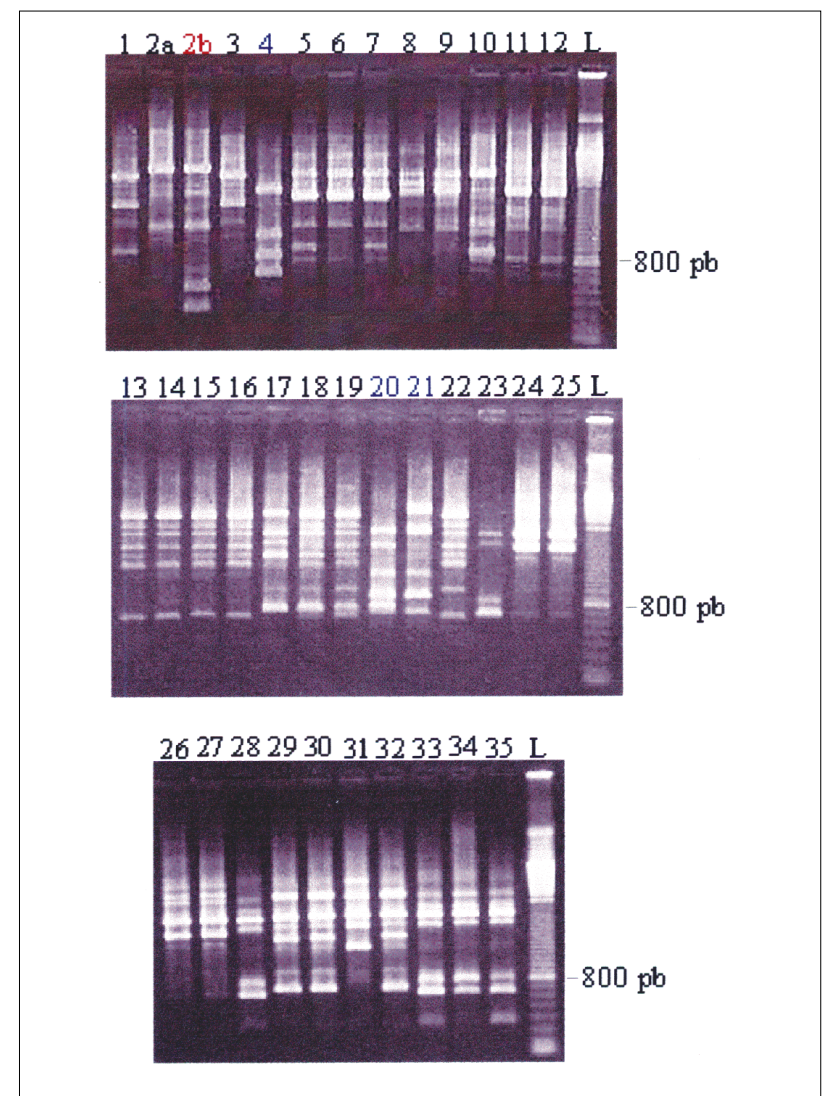

Figura 3 - RAPD-PCR: Produtos de amplificação do DNA de cepas de Vibrio cholerae não 01 com primer 791 - São Luís/MA (1997-1998). L= ladder, pb= parde bases. Linhas 1, 2a, 3, 5-19, 22-30, 32-35=V. cholerae não 01. Linha 2b= V. alginolyticus; Linha 31= Vibrio sp, linhas 4,20,21= V. parahaemolyticus.

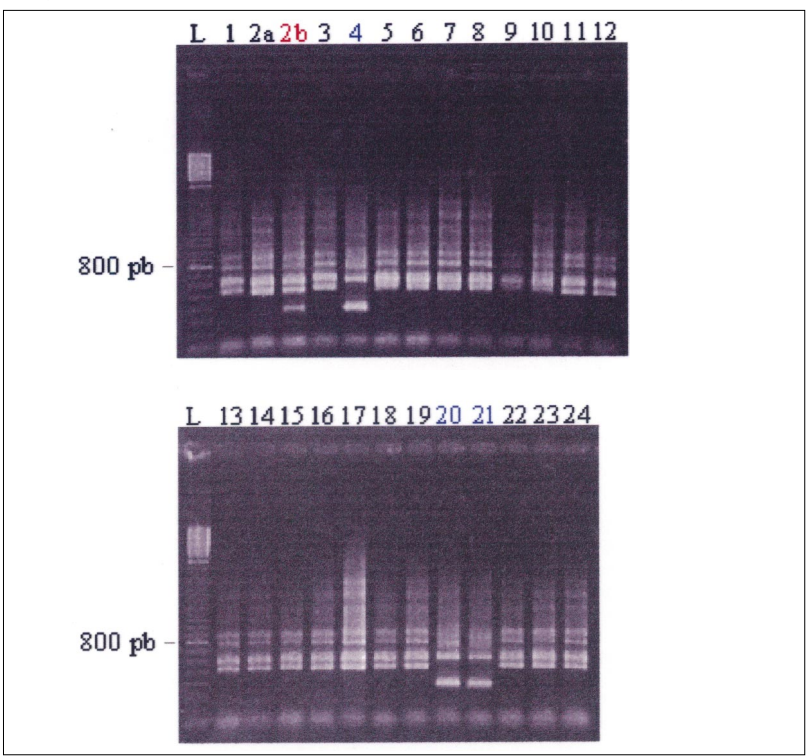

Figura 4 - Ribotipagem - gel representativo dos produtos da amplificação por PCR de cepas não 01 deVibrio cholerae - São Luis/MA(1997-1998). L= ladder, $\mathrm{pb}=$ par de bases. Linhas 1, 2a, 3, 5-19, 22-30, 32-35=V. cholerae não 01. Linha 2b= V. alginolyticus; Linhas 4, 20, 21= V. parahaemolyticus. 


\section{DISCUSSÃ0}

0 emprego de técnicas moleculares no estudo da espécie Vibrio cholerae, tem tornado possível um melhor entendimento do potencial de variabilidade genética, de virulência e da dinâmica de transferência horizontal de genes entre diferentes sorogrupos. A presença do cassete VCR, envolvido na expressão do gen sto ( toxina termo-estável) foi demonstrada em sorogrupos diversos de V. cholerae, assim como em outras espécies de Vibrio ${ }^{16}$. Mais recentemente, foi identificada por Karaolis et al $^{12}$ a Ilha de Patogenicidade do V. cholerae (VPI), onde se situa 0 operon que codifica o pili co-regulado com a toxina, em cepas toxigênicas de $\mathrm{V}$. cholerae não $01^{12}$. Em estudo de 41 isolados de V. cholerae não 01, provenientes das regiões Norte e Nordeste do Brasil, foram detectadas sequiências compatíveis com os genes toxT e tcpA em uma proporção das cepas ${ }^{17}$. Estes dados, aliados à emergência do sorogrupo 0139 como patógeno capaz de produzir doença diarréica semelhante à cólera clássica, reforçam a importância que a espécie Vibrio cholerae assume no campo da patologia humana.

Apresença de plasmídeos em 10 cepas é comparável ao achado de outros pesquisadores que os demonstraram em sorogrupos não 01 de Vibrio cholerae ${ }^{21718}$. A função exercida por estas estruturas não está bem definida em V. cholerae, sendo considerados crípticos, uma vez que a retirada deles por passagens sucessivas in vitro não alterou as características de virulência das cepas bacterianas ${ }^{18}$. Padrão similar de atividade hemaglutinante, citotóxica e enterotóxica foi constatado entre cepas de V. cholerae, portadoras ou não de plasmídeos numa evidência de que essas características nem sempre são mediadas por eles². Contudo, em algumas cepas foram detectados plasmídeos que abrigavam genes de resistência a múltiplos antibióticos, transferíveis a outros grupos bacterianos.

A ausência dos genes ctxA, ace e zot pela técnica de PCR são comparáveis aos resultados encontrados em estudo de cepas ambientais de V. cholerae 01 e não 01 isoladas antes e durante epidemia de cólera no Estado de São Paulo, o qual demonstrou que os isolados de $\mathrm{V}$. cholerae 01 relacionados à epidemia continham os genes ctxAe zot, enquanto os pré-epidêmicos e todos os não 01 eram negativos ${ }^{21}$. No entanto, apesar de não ser comum 0 encontro de cepas produtoras da toxina termolábil, característica da cólera, em cepas ambientais de V. cholerae não 01 , a produção de citotoxinas e enterotoxinas semelhantes à toxina colérica foi demonstrada em ensaios laboratoriais, demonstrando 0 potencial de patogenicidade contido nessas cepas ${ }^{11} 192225$.

A ribotipagem revelou apenas um perfil, evidenciando a circulação de um único ribotipo no ambiente estudado. № entanto, a identificação de múltiplos perfis genéticos entre os 31 isolados submetidos à RAPD-PCR corrobora as observações de outros autores quanto ao grande potencial de variabilidade apresentada pela espécie V. cholerae ${ }^{101224}$. Levando-se em conta a distribuição dos isolados nas 4 estações de amostragem, constata-se que as cepas são, em geral, provenientes do mesmo estuário, ainda que de estações diferentes. № entanto, com 0 grupo formado com os isolados 17, 1819 e 22, os quais apresentam 0 mesmo perfil com 0 iniciador 791 a procedência foi diversificada, tendo sido o isolado 17 obtido de amostra coletada na estação 1 do rio Bacanga, enquanto os outros 3 são provenientes da estação 2 do rio Anil. Com 0 iniciador 784, com 0 qual foram definidos 7 perfis distintos, os agrupamentos são formados por maior número de isolados, observando-se que, em relação à distribuição espacial, repete-se 0 padrão descrito com 0 iniciador 791. Observou-se, ainda, em relação aos meses de coleta que alguns isolados com perfil idêntico foram obtidos a partir de amostras coletadas em meses diferentes, como no caso dos isolados 13, 14 (fevereiro/98), 15 e 16 (março/98). Estas observações sugerem um comportamento dinâmico da espécie, condicionado, provavelmente, pelas variações das condições ambientais, as quais poderiam selecionar a predominância de determinado genótipo em épocas e locais diferentes.

\section{AGRADECIMENTOS}

À equipe do Departamento de Microbiologia, do Centro de Pesquisas Aggeu Magalhães/FIOCRUZ, Recife-PE, pelo apoio técnico no processamento das amostras

\section{REFERÊNCIAS BIBLIOGRÁFICAS}

1. Albert MJ. Personal reflections on discovery of Vibrio cholerae 0139 synonym Bengal: a tribute to team work and international collaboration. Journal of Diarrhoeal Disease Research 11: 207-210, 1993.

2. Barja JL, Santos I, Huq I, Colweel, RR, Toranzo AE. Plasmids and factors associated with virulence in environmental isolates of Vibrio cholerae non01 in Bangladesh. Journal of Medical Microbiology 33: 107-114, 1990.

3. Bhattacharji LM, Bose B. Field and laboratory studies on transformation of the $\mathrm{V}$. cholerae in the maintenance of cholera endemicity: a preliminary report. Indian Journal of Medical Research 52: 777-790, 1964.

4. Birnboim HC, Doly J. A rapid alkaline extraction procedure for screening recombinant plasmid DNA. Nucleic Acids Research 7:1513-1523, 1979.

5. Chun J, Huq A, colwell RR. Analysis of 16S-23S r RNA intergenic spacer regions of Vibrio cholerae and Vibrio mimicus. Applied and Environmental Microbiology 65: 2202-2208, 1999.

6. Colweel RR, Huq A, Chowdhury MAR, Brayton PR, Xu B. Serogroup conversion of Vibrio cholerae. Canadian Journal of Microbiology 41: 946 950, 1995

7. Heidelberg JF, Elsen JA, Nelson WC, Clayton RA, Gwinn ML, Dodson RJ, Haft DH, Hickey EK, Peterson JD, Umayam L, Gill SR, Nelson KE, Read TD, Tettelin H, Richardson D, Ermolaeva MD, Vamathevan J, Bass S, Qin H, Dragol I, Sellers P, McDonald L, Utterback T, Fleishman RD, Nierman WC, White 0, Salzberg SL, Smith HO, Colwell RR, Mekalanos JJ, Venter JC, fraser CM. DNA sequence of both chromosomes of the cholera pathogen Vibrio cholerae. Nature 406: 477-482, 2000.

8. Hofer E. Métodos utilizados para o isolamento e identificação de Vibrio cholerae. Informe de Patologia Clínica 1: 5-18, 1975.

9. Huq A, Small EB, West PA, Huq MI, Rahman R, Colweell RR. Ecological relationship between Vibrio cholerae and planktonic crustacean copepods. Applied and Environmental of Microbiology 45: 275-283, 1983.

10. Jiang SC, Louis V, Choopun N, Sharma A, Huq A, Colwell RR. Genetic diversity of Vibrio cholerae in Chesapeake Bay determined by amplified fragment length polymorphism fingerprinting. Applied and Environmental of Microbiology 66: 140-147, 2000.

11. Kaper JB, Lockman H, Colwell RR, Joseph SW. Ecology, serology and enterotoxin production of Vibrio cholerae in Chesapeake Bay. Applied and Environmental of Microbiology 37: 91-103, 1979. 
12. Karaolis DKR, Somara S, Maneval DR, Johnson JA, Kaper JB. A bacteriophage encoding a pathogenicity island, a type-IV pillus and phage receptor in cholera bacteria. Nature 399: 375-379, 1999.

13. Keasler SP, Hall RH. Detecting and biotyping V. cholerae 01 with multiplex Polimerase Chain Reaction. Lancet 341: 1661, 1993.

14. Kostman JR, Edlind TD, Lipuma JJ, Stull TL. Molecular epidemiology of Pseudomonas cepacia determined by Polymerase Chain Reaction Ribotyping. Journal of Clinical Microbiology 30: 2084-2987, 1992.

15. Maniatis T, Fritsch EF, Sambroock J. Molecular Cloning: A Laboratory Manual. Cold Spring Harbor Laboratory Press, Cold Spring Harbor. New York. 368-369, 1982.

16. Mazel D, Dychinco B, Webb VA, Davies J. A distinctive class of integron in the Vibrio cholerae genome. Science 280: 605-608, 1998.

17. Melo FBS. Fatores de virulência em Vibrio cholerae das regiões Norte e Nordeste do Brasil. Tese de Mestrado. Recife, PE, 1998.

18. Nandy RK, Sengupta TK, Mukhopadhyay S, Ghose AC. A comparative study of properties of Vibrio cholerae 0139, 01 and other non-01 strains. Journal of Medical Microbiology 42: 251-257, 1995.
19. Ohashi M, Shimada T, Fulcumi H. "In vitro" production of enterotoxin and hemorrhagic principle by V. cholerae NAG. Japanese Journal of Medical Science and Biology 25: 179-194, 1972.

20. Pollitzer R. Cholera: Monograph 43. World Health Organization Geneva. Switzerland, 1959.

21. Rivera IG, Chowdhury MAR, Sanchez PS, Sato MI, Huq A, Colweel RR, Martins MT. Detection of cholerae toxin (ctx) and zonula ocludens (zot) genes in Vibrio cholerae 01, 0139 and non-01 strains. Journal of Microbiology and Biotechnology 11: 572-577, 1995 .

22. Saha PK, Kolley H, Nair GB. Purification and characterization of an extracellular secretogenic non-membrane-damaging cytotoxin produced by clinical strains of Vibrio cholerae non-01. Infection and Immunity 64: 3101-3108, 1996.

23. Shimada T, Arakawa E, Itoh HK, Okitsu T, Matsushima A, Asai Y, Yamai S, Nakazato T, Nair G B, Albert M J, Takeda Y. Extended serotyping scheme for V. cholerae. Current Microbiology 28: 175-178, 1994.

24. Waldor MK, Mekalanos JJ. Lysogenic conversion by a filamentous phage encoding cholera toxin. Science 277: 1910-1914, 1996.

25. Zinnaka Y, Carpenter CCJ. An enterotoxin produced by noncholera vibrios. Johns Hopkins Medical Journal 131: 403-410, 1972. 